\title{
Ephemeral Wetland Vegetation of the Ob River in the Forest-Steppe Zone of Western Siberia
}

\author{
Georgy S. Taran* \\ West-Siberian Division \\ of V.N. Sukachev Institute of Forest of SB RAS \\ 100/1 Zhukovskogo Str., Novosibirsk, 630082, Russia
}

Received 06.02.2017, received in revised form 06.03.2017, accepted 21.03.2017, published online 12.11.2017

Ephemeral wetland vegetation of the Ob River is defined within the limits of Novosibirsk Region and Altai Territory, Russia. Association Cypero fusci-Limoselletum aquaticae (Oberd. 1957) Korneck 1960 (Eleocharition soloniensis Philippi 1968, Nanocyperetalia Klika 1935, Isoëto-Nanojuncetea) prevails on the Ob River low water banks in the forest-steppe zone. On the Ob River, it is represented by subassociation Cypero fusci-Limoselletum aquaticae riccietosum frostii subass. nov. Communities of Peplido alternifoliae-Alismatetum graminei ass. nov. (Nanocyperion Koch 1926, Nanocyperetalia) develop on dirt roads of the riparian zone high levels in high-water years. The new association diagnostic species are Lindernia procumbens and Scirpus supinus. Subassociation Cypero-Limoselletum scirpetosum lateriflori Taran 1995 is transferred to the Peplido alternifoliae-Alismatetum graminei association as variant Cyperus fuscus. The author's data defining ephemeral wetland vegetation of the forest-steppe zone of Western Siberia (73 relevés), including subassociation Eleocharito-Caricetum bohemicae gnaphalietosum rossici Taran 1995 dominating on the low water banks of the Biya River lower course, are summed up in the synoptic table.

Keywords: syntaxonomy, new syntaxa, relevés, Cypero fusci-Limoselletum aquaticae, Peplido alternifoliae-Alismatetum graminei, Isoëto-Nanojuncetea.

Citation: Taran G.S. Ephemeral wetland vegetation of the Ob River in the forest-steppe zone of Western Siberia. J. Sib. Fed. Univ. Biol., 2019, 12(1), 15-31. DOI: 10.17516/1997-1389-0032.

(C) Siberian Federal University. All rights reserved

* Corresponding author E-mail address: gtaran@mail.ru 


\title{
Пойменный эфемеретум р. Оби \\ в лесостепной зоне Западной Сибири
}

\author{
Г.С. Таран \\ Западно-Сибирское отделение \\ Института леса им. В.Н. Сукачева СО РАН \\ Россия, 630082, Новосибирск, ул. Жуковского, 100/1
}

\begin{abstract}
Пойменный эфемеретум р. Оби охарактеризован в пределах Новосибирской области и Алтайского края (Россия). В лесостепной зоне на меженных отмелях р. Оби преобладает accouииация Cypero fusci-Limoselletum aquaticae (Oberd. 1957) Korneck 1960 (союз Eleocharition soloniensis Philippi 1968, порядок Nanocyperetalia Klika 1935, класс Isoёto-Nanojuncetea). На Оби она представлена субассочиаџией Cуреro fusci-Limoselletum aquaticae riccietosum frostii subass. nov. На грунтовых дорогах высоких уровней прирусловой поймы в годы высоких половодий развиваются сообщества ассочиации Peplido alternifoliae-Alismatetum graminei ass. nov. (союз Nanocyperion Koch 1926, порядок Nanocyperetalia). Диагностические виды новой ассоциации Lindernia procumbens u Scirpus supinus. Субассощиация Cypero-Limoselletum scirpetosum lateriflori Taran 1995 перенесена в ассочиаиию Peplido alternifoliae-Alismatetum graminei в качестве варианта Cуретиs fuscus. Материаль автора по пойменному эфемеретуму лесостепной зонь Западной Сибири (73 описания), включая субассоциацию Eleocharito-Caricetum bohemicae gnaphalietosum rossici Taran 1995, доминирующую на меженных отмелях нижнего течения р. Бии, подытожены в синоптической таблице.
\end{abstract}

Ключевые слова: синтаксономия, новые синтаксоны, геоботанические описания, Сурето fusciLimoselletum aquaticae, Peplido alternifoliae-Alismatetum graminei, Isoëto-Nanojuncetea.

\section{Введение}

Недолговечные сообщества аллювиальных эфемеров, обитающих в поймах крупных рек Северной Евразии, в классификации растительности по методу Браун-Бланке входят в класс Isoëto-Nanojuncetea (Pietsch, 1973; Deil, 2005). В русской научной литературе они известны как пойменный эфемеретум (Шенников, 1938; Горчаковский, Пешкова, 1970; Таран, 1995). В Западной Сибири пойменный эфемеретум лучше всего изучен в пределах таежной зоны (Таран, 1994, 2001, 2005, 2009; Таран, Тюрин, 2006; Таран, Саодатова, 2008). Сведений по югу гораздо меньше (Таран, 1995; Киприянова,
2008). Цель статьи - дать детальную синтаксономическую характеристику сообществам пойменного эфемеретума, распространенным на лесостепном отрезке р. Оби и в нижнем течении р. Бии.

\section{Материалы и методы}

Материалы (49 описаний; далее - оп.) собраны в 1991-2007 гг., главным образом, в пойме р. Оби (рис. 1). Новосибирская область: 1) Колыванский р-н, пгт. Колывань 2 км на северо-восток, правый берег р. Чаус (1 оп., 1991 г.); 2) Сузунский р-н, с. Верхний Сузун, берег р. Оби в устье р. Верхний Сузун (5 оп., 1994 г.); 3) Сузунский р-н, с. Мереть, бе- 


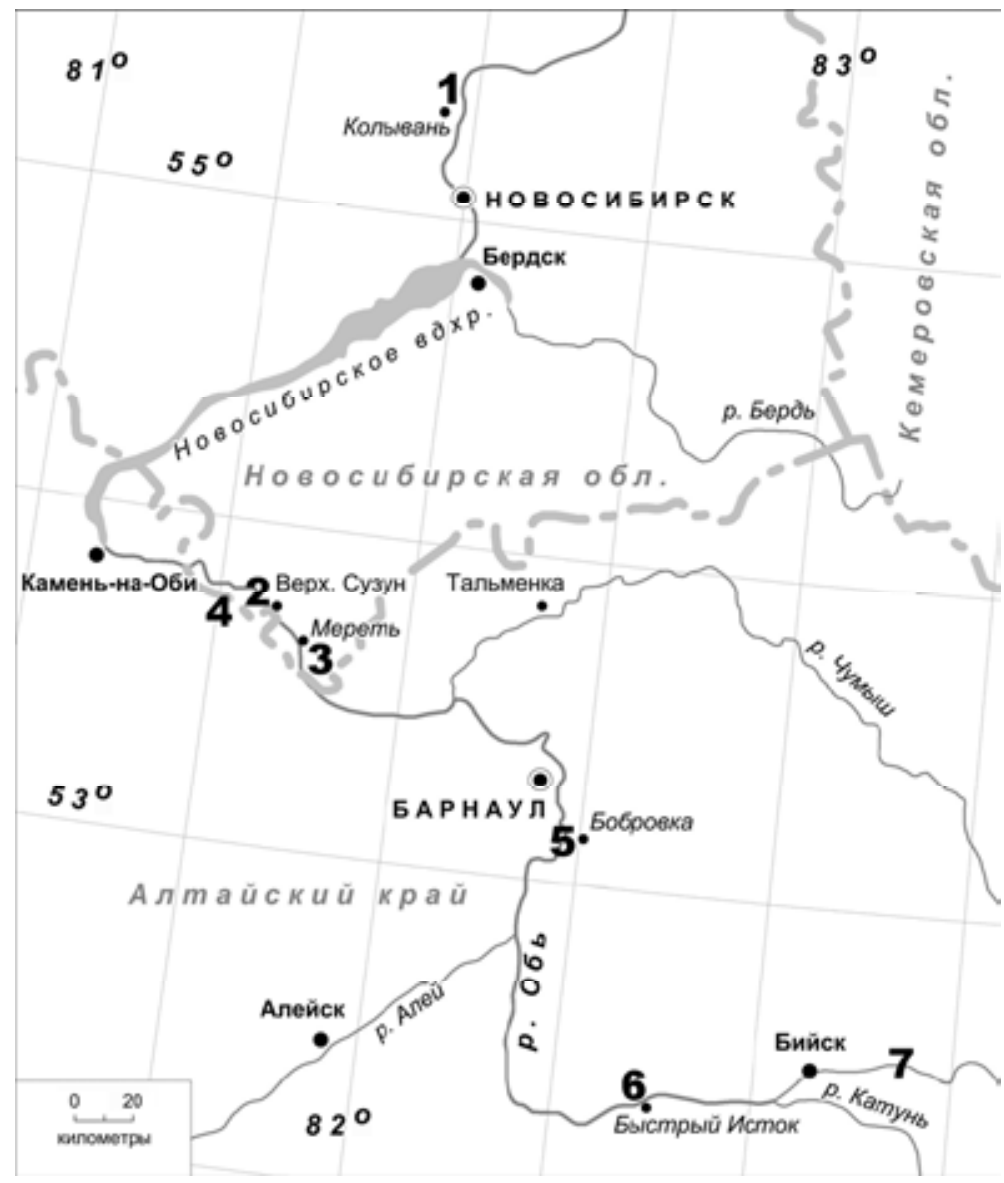

Рис. 1. Расположение ключевых участков (№№ 1-7) в пойме р. Оби. Пояснения в тексте

Fig. 1. The location of the key areas (Nos. 1-7) in the Ob River floodplain. Explanations are in the text

рег протоки (1 оп., 1996 г.). Алтайский край:

4) Каменский p-н, левый берег протоки Заломная, 18 км на запад от с. Верхний Сузун, участок к югу от урочища Конский Луг (10 оп., 2006 г.); 5) Первомайский р-н, с. Бобровка и окрестности, острова и берега р. Оби (27 оп., 1992 г.); 6) Быстроистокский р-н, окр. с. Быстрый Исток, о-в Сосновый (3 оп., 2007 г.); 7) Бийский р-н, остров на р. Бии к востоку от с. Стан-Бехтемир (2 оп., 1994 г.). Привязка ключевых участков к природным зонам: № 1 северная, № 2-5 - центральная, № 6 - южная лесостепь, № 7 - предгорная степь. Природное районирование дано по И.С. Ильиной с соавт. (1985).
При изучении обширных ценозов пойменного эфемеретума использовались учетные площадки (УП) в 10 м². Ценозы меньших размеров описывались в естественных границах. Проективное покрытие (ПП) видов оценивалось в процентах, а для представления в статье переведено в баллы: «г» - не более $0,01 \%$, «+» - более 0,01 , но менее $1 \%$; «1»-1-5\%; «2»-6-12\%; «3»- 13-25\%; «4»-26-50\%; «5»-51-75\%; «6»-76-100\%. В ряде случаев на УП замерялись толщина ила на поверхности субстрата и уровень грунтовых вод (УГВ).

Образцы рода Riccia (Hepaticae), собранные на отмелях Оби и нижней Бии, опреде- 
лил В.А. Бакалин (Бакалин, Таран, 2004). Отдельные образцы сосудистых растений определили М.Н. Ломоносова (Eragrostis amurensis), В.В. Зуев (Spergularia diandra), Eisuke Hayasaka (Scirpus supinus), H.H. Тупицына (Polygonum arenastrum, P. neglectum, Persicaria foliosa).

При обработке описаний применялась интегрированная ботаническая информационная система IBIS (Зверев, 2007). Оценка синтаксономической принадлежности описаний проведена на основе классических представлений о структуре и объеме ассоциаций класса Isoëto-Nanojuncetea (Pietsch, 1973; Philippi, 1992; Täuber, 2000), выделение новых синтаксонов проведено по правилам Международного кодекса фитосоциологической номенклатуры (Weber et al., 2000). Виды сосудистых растений, мхов и печеночников указываются соответственно по С.К. Черепанову (1995), M.S. Ignatov et al. (2006), N.A. Konstantinova et al. (2009). Гидроморфологические термины даются по Н.Е. Кондратьеву с соавт. (1982).

\section{Результаты и обсуждение}

В табл. 1 представлен необычный вариант пойменного эфемеретума, который можно назвать «дорожным». В пойме Оби он редок, занимает малые площади и наблюдается после высоких половодий. Оп. 1-10 сделаны на сырых грунтовых дорогах, пересекающих безлесные луговые участки высокого берега протоки Заломной (Каменский р-н). В 2006 г. эти дороги полностью затоплялись.

Основное отличие «дорожного» эфемеретума от аналогов, наблюдаемых на меженных отмелях Оби, - высокое постоянство, а порой и обилие редких в Западной Сибири видовэфемеров: Lindernia procumbens, Scirpus supinus и Peplis alternifolia.
Популяция однолетнего камыша, обитающая на юге Западной Сибири, во «Флоре Сибири» делится на два вида: Scirpus supinus и Scirpus lateriflorus. Признаком, по которому S. lateriflorus отделяется от S. supinus, считается наличие второго прицветного листа (Тимохина, 1990). Подобные экземпляры камыша, собранные у сел Мереть и Верхний Сузун, японский таксономист Eisuke Hayasaka, обработавший род Schoenoplectus в мировом масштабе, определил как Schoenoplectus supinus (L.) Palla (Hayasaka, 2002). Согласно С.К. Черепанову (1995), я привожу этот вид как Scirpus supinus L.

Своеобразие видового состава и экотопической приуроченности сообществ «дорожного» эфемеретума дают основание принимать их в качестве новой ассоциации: Peplido alternifoliae-Alismatetum graminei ass. nov. hoc loco. Номенклатурный тип (holotypus) - оп. 2 в табл. 1: полевой номер 8, 26.07.2006, Алтайский край, Каменский p-н, пойма Оби - 18 км на запад от с. Верхний Сузун, высокий левый берег протоки Заломной, 5339'48,0" с.ш., 8159'37,5" в.д., межколейное повышение сырой грунтовой дороги; Г.С. Таран. Диагностические виды ассоциации: Scirpus supinus, Lindernia procumbens. К локальным диагностическим видам, отличающим эту ассоциацию от местных сообществ обского отмельного эфемеретума, можно отнести Alisma gramineum, Polygonum aviculare aggr. Последний представлен двумя видами более мелкого объема: Polygonum arenastrum (оп. 1) и P. neglectum (оп. 2, 3).

По характеру местообитаний (сырые дороги высоких уровней поймы) acc. Peplido alternifoliae-Alismatetum graminei можно уверенно отнести к союзу Nanocyperion Koch 1926 порядка Nanocyperetalia Klika 1935 (Pietsch, 1973; Таран, 1995). Из выявленных на территории России ассоциаций «дорожного» эфеме- 
Таблица 1. Ассоциация Peplido alternifoliae-Alismatetum graminei ass. nov.

Table 1. Association Peplido alternifoliae-Alismatetum graminei ass. nov.

\begin{tabular}{|l|c|c|c|c|c|c|c|c|c|c|c|}
\hline \multicolumn{1}{|c|}{ Номер описания } & 1 & 2 & 3 & 4 & 5 & 6 & 7 & 8 & 9 & 10 & П-во \\
\hline Полевой номер & $6 / 7$ & 8 & 9 & 10 & 11 & 12 & 13 & 14 & 15 & 16 & \\
\hline Дата в 2006 г., день.месяц & 26.7 & 26.7 & 26.7 & 26.7 & 27.7 & 28.7 & 28.7 & 29.7 & 29.7 & 31.7 \\
\hline Площадь описания, м ${ }^{2}$ & 1,2 & 1,3 & 1,3 & 1,7 & 1,7 & 0,6 & 0,7 & 1,6 & 1,8 & 1,0 \\
\hline Высота травостоя*, см & $25 / 3$ & 30 & 25 & 30 & $35 / 12$ & $20 / 3$ & $30 / 2$ & 15 & 15 & $25 / 3$ \\
\hline ОПП травостоя, \% & 35 & 35 & 35 & 35 & 30 & 30 & 35 & 90 & 90 & 70 \\
\hline Число видов сосудистых & 23 & 20 & 23 & 24 & 16 & 18 & 13 & 27 & 30 & 15 & \\
\hline
\end{tabular}

Д.в. acc. Peplido alternifoliae-Alismatetum graminei

Lindernia procumbens

Scirpus supinus

Polygonum neglectum + P. arenastrum (loc.)

Д.в. класса Isoёto-Nanojuncetea

Alisma gramineum

Limosella aquatica

Peplis alternifolia

Alisma bjoerkqvistii

Д.в. класcа Isoëto-Nanojuncetea

Alisma plantago-aquatica

Juncus compressus

Veronica anagallis-aquatica

Eleocharis palustris

Lythrum virgatum

Plantago major

Callitriche palustris

Echinochloa crusgalli

Rorippa palustris

Equisetum arvense

Agrostis gigantea

Inula britannica

Taraxacum officinale

Amoria repens

Chenopodium glaucum

Kadenia dubia

\begin{tabular}{|cccccccccc|c|}
1 & 3 & 2 & 3 & 2 & 1 & 1 & 1 & 1 & 1 & $\mathrm{~V}^{12}$ \\
3 & 1 & 1 & 1 & $\cdot$ & 2 & 2 & + & + & 5 & $\mathrm{~V}^{+2}$ \\
+ & + & + & $\mathrm{r}$ & + & $\cdot$ & $\cdot$ & + & $\cdot$ & $\cdot$ & III \\
. & $\cdot$ &. &. & 2 & 2 &. & + & + &. & II
\end{tabular} \mid

Д.в. класcа Phragmito-Magnocaricetea

$$
\begin{array}{|cccccccccc|c}
+ & + & 1 & + & 1 & 1 & 1 & 1 & + & 1 & \mathrm{~V}^{+1} \\
+ & 1 & 1 & + & . & + & + & + & . & 1 & \mathrm{IV}^{+1} \\
1 & + & + & 2 & 1 & + & \cdot & \cdot & . & 1 & \mathrm{IV}^{-1} \\
+ & \cdot & \cdot & \cdot & + & + & 1 & 1 & + & + & \mathrm{IV} \\
+ & + & + & \mathrm{r} & . & + & . & + & + & . & \mathrm{IV}
\end{array}
$$

Прочие виды

Примечание. С невысоким постоянством отмечены: сосудистые - Agrostis stolonifera 1(+); Allium angulosum 9(+); Amaranthus retroflexus 9(+); Beckmannia syzigachne 1(+); Bolboschoenus maritimus 5(+); Carex acuta 8(1); C. praecox 8(1); Chenopodium album 8(+), 9(+); Cirsium setosum 8(+), 9(+); Dracocephalum nutans 8(+); Elytrigia repens 8(1), 9(1); Filaginella rossica 1(+), 8(+); Galium boreale 9(1); G. palustre 4(+); Geranium sibiricum 3(+j); Gratiola officinalis 1(+), 9(+); Juncus articulatus 5(+), 8(+); Lysimachia vulgaris 9(1); Persicaria amphibia 9(1); P. foliosa 5(+); P. hydropiper 1(+), 4(+); P. minor 4(+), 6(+); Picris hieracioides 9(+); Poa angustifolia $8(+)$; Populus nigra $8(+\mathrm{j}), 9(+\mathrm{j})$; Potentilla anserina 4(+); P. flagellaris $8(+), 9(+) ;$ P. norvegica $3(+\mathrm{j}), 4(+\mathrm{j}) ;$ P. supina ssp. paradoxa $9(+) ;$ Ptarmica cartilaginea $9(+) ;$ Ranunculus repens $2(+\mathrm{j})$, 9(1); Rumex pseudonatronatus 4(+); R. thyrsiflorus 9(+); Salix alba 2(+j); Scabiosa ochroleuca 3(+j); Sonchus arvensis $6(+)$; Thalictrum sp. 1(+j), 3(rj); Typha angustifolia 10(+); T. latifolia 8(+); печеночники - Riccia cavernosa 4(r); R. frostii 4(r). *- В оп. 1, 5-7 и 10 травостой двухъярусный; числа, обозначающие высоты 1-го и 2-го ярусов, разделяются косой чертой. Условные индексы: «Д.в.»- диагностический вид; (loc.) - локальный д.в.; «ј» справа от балла ПП означает, что вид на УП представлен всходами; «П-во» - постоянство. Классы постоянства: «+» - не более 10 \%; I - 11-20 \%; II - 21-40\%; III - 41-60\%; IV - 61-80\%; V - 81-100\%. Для обильных видов в таблицах 1 и 4 справа от класса постоянства надстрочными цифрами указан межквартильный диапазон (25 \% - 75 \%) варьирования ПП, выраженного в баллах ПП:

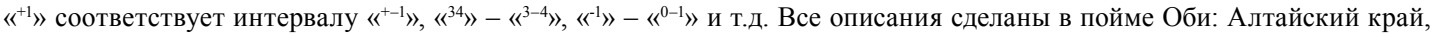
Каменский р-н, левобережье протоки Заломной, 18 км на запад от с. Верхний Сузун. 
ретума к acc. Peplido alternifoliae-Alismatetum graminei наиболее близка acc. Androsaco filiformis-Peplidetum alternifoliae Solm. et al. 1994, описанная из лесостепей Башкирии (Соломещ и др., 1994). Acc. Androsaco-Peplidetum характеризуется ясно выраженным доминированием заглавных видов (Peplis alternifolia $\mathrm{V}^{12}$, Androsace filiformis $\left.\mathrm{IV}^{22}\right)$ и бедным набором спутников-эфемеров (Juncus bufonius $\mathrm{V}^{\mathrm{r}+}$, Gnaphalium uliginosum s.l. $\mathrm{V}^{\mathrm{r}+}$, Psammophiliella muralis $\mathrm{III}^{-+}$).

Среди синтаксонов союза Nanocyperion, известных в зарубежной Европе (Pietsch, 1973), с наибольшим постоянством (III класc) Scirpus supinus зарегистрирован в асс. Lythro hyssopifoliae-Gnaphalietum luteo-albi (Bodrogközy) Pietsch 1961. Последняя отличается от приводимых мною сообществ (табл. 1) более богатым набором видов-эфемеров. В ней c IV-V классами постоянства отмечены Lythrum hyssopifolium, Gnaphalium luteoalbum, Filaginella uliginosa, Juncus bufonius, Centaurium pulchellum, Cyperus fuscus, но отсутствует Lindernia procumbens. Линдернии нет и в других ассоциациях союза Nanocyperion (Pietsch, 1973).

В Обь-Иртышском бассейне только асс. Marisco hamulosi-Crypsietum schoenoidis Taran 1993 характеризуется высоким постоянством Lindernia procumbens и Scirpus supinus (V и III классы). Эта ассоциация, отнесенная в протологе (Таран, 1993) в союз Elatini-Eleocharition ovatae Pietsch 1965 (его ныне принятое название - Eleocharition soloniensis Philippi 1968), распространена на полупустынном отрезке Черного Иртыша, где занимает естественные, первичные местообитания: низкие отмели прирусловой зоны.

Acc. Peplido alternifoliae-Alismatetum graminei, напротив, занимает вторичные местообитания, в которых луговая дернина нарушена транспортом: грунтовые дороги вы- соких уровней поймы, заливаемые в самые многоводные годы. Название расположенного по соседству урочища (Конский Луг) наводит на мысль, что некогда здесь выпасали коней. В дикой природе этим дорогам и выпасам, вероятно, соответствовали сырые тропы и места водопоя копытных: лосей, оленей, тарпанов, туров (Таран, 1995). В отношении Lindernia procumbens и Scirpus supinus грунтовые дороги лесостепного отрезка поймы Оби можно расценивать как экстразональные экотопы.

Из местных синтаксонов пойменного эфемеретума к этой ассоциации близка субасс. Cypero-Limoselletum scirpetosum lateriflori Taran 1995, описанная из окрестностей с. Верхний Сузун (Таран, 1995). Оба синтаксона сходны по характеру экотопа (сырые грунтовые дороги высоких уровней поймы, затопляемые в годы высоких половодий), погодичной динамике («дорожный» эфемеретум появляется в годы, когда отмельный не развивается из-за позднего освобождения отмелей от воды) и наличию либо высокому постоянству Scirpus supinus, Peplis alternifolia, Callitriche palustris, Alisma gramineum, Alisma plantago-aquatica, Polygonum aviculare aggr. Субассоциацию C.-L. scirpetosum lateriflori я перевожу в асc. Peplido-Alismatetum в качестве варианта Cyperus fuscus. По набору видов-эфемеров этот вариант занимает промежуточное положение между асc. PeplidoAlismatetum и Cypero-Limoselletum.

Пойменный эфемеретум низких высотных уровней, развивающийся на меженных отмелях в маловодные годы, представлен в оп. 11-48 (табл. 2, 3). Они относятся к асс. Cypero fusci-Limoselletum aquaticae (Oberd. 1957) Korneck 1960. Диагностические виды ассоциации - Limosella aquatica, Cyperus fuscus. Согласно продромусу высших единиц растительности Европы (Mucina et al., 2016), синтаксономическое положение асc. Cypero- 
Таблица 2. Субасc. Cypero fusci-Limoselletum aquaticae riccietosum frostii; фации cyperosum fusci (11-20), salicosum albae (21), filaginellosum rossicae (22-24), ricciosum frostii (25-26), linderniosum procumbentis (27)

Table 2. Subass. Cypero fusci-Limoselletum aquaticae riccietosum frostii; facies cyperosum fusci (11-20), salicosum albae (21), filaginellosum rossicae (22-24), ricciosum frostii (25-26), and linderniosum procumbentis (27)

\begin{tabular}{|l|c|c|c|c|c|c|c|c|c|c|c|c|c|c|c|c|c|}
\hline \multicolumn{1}{|c}{ Номер описания } & 11 & 12 & 13 & 14 & 15 & 16 & 17 & 18 & 19 & 20 & 21 & 22 & 23 & 24 & 25 & 26 & 27 \\
\hline Площадь описания, ${ }^{2}$ & 6 & 2,5 & 2 & 5 & 2 & 5 & 10 & 10 & 10 & 10 & 1,6 & 1 & 4 & 2 & 10 & 10 & 0,9 \\
\hline Высота травостоя, см & 3 & 2 & 6 & 8 & 8 & 8 & 10 & 8 & 12 & 12 & 8 & 4 & 10 & 10 & 12 & 10 & 4 \\
\hline ОПП полное, \% & 30 & 50 & 50 & 60 & 60 & 60 & 50 & 100 & 40 & 55 & 20 & 35 & 40 & 50 & 45 & 40 & 50 \\
\hline ОПП* всходов Salicaceae, \% & $\mathrm{r}$ & $\mathrm{r}$ & $\mathrm{r}$ & 0 & 0 & $\mathrm{r}$ & 3 & + & + & + & 11 & $\mathrm{r}$ & + & + & + & $\mathrm{r}$ & + \\
\hline ОПП травостоя, \% & 28 & 50 & 50 & 60 & 60 & 60 & 45 & 45 & 40 & 45 & 4 & 35 & 35 & 50 & 5 & 7 & 50 \\
\hline ОПП мохообразных, \% & 5 & 2 & 10 & 2 & 2 & + & 3 & 40 & 3 & 16 & 5 & 1,5 & 15 & 5 & 40 & 35 & 3 \\
\hline ПП Вотгудіит granulatum, \% & 0 & 0 & 0 & 0 & 0 & + & 1 & 55 & 0 & 0 & 0 & + & 0 & + & 0 & + & + \\
\hline Число видов сосудистых & 29 & 23 & 18 & 16 & 16 & 22 & 46 & 30 & 54 & 44 & 21 & 21 & 20 & 20 & 20 & 22 & 11 \\
\hline Число видов мохообразных & 2 & 2 & 2 & 2 & 2 & 3 & 3 & 3 & 3 & 3 & 3 & 2 & 2 & 2 & 3 & 3 & 2 \\
\hline Толщина ила, см & 25 & 25 & 16 & 13 & 35 & 20 & 1 & 1.5 & - & 9 & 2 & 10 & - & 40 & - & 10 & - \\
\hline Уровень грунтовых вод, см & $77^{+}$ & $77^{+}$ & - & $87^{+}$ & 100 & - & 5 & 5 & - & - & 40 & - & - & - & - & - & - \\
\hline
\end{tabular}

Д.в. асc. Cypero-Limoselletum и субасc. C.-L. riccietosum frostii

Cyperus fuscus

Limosella aquatica

D Riccia frostii

Plantago intermedia

Filaginella rossica

D Physcomitrella patens

Eragrostis amurensis

D Botrydium granulatum

D Riccia cavernosa

Eleocharis acicularis f. annua

Dichostylis micheliana

Lindernia procumbens

Salix alba (juv.)

Populus nigra (juv.)

Salix triandra (juv.)

$$
\left|\begin{array}{rrrrrrrrrr|r|rrr|rr|r}
3 & 4 & 4 & 4 & 5 & 4 & 4 & 4 & 4 & 3 & 1 & 1 & + & + & + & + & 3 \\
+ & + & + & + & \mathrm{r} & + & + & 1 & + & \cdot & + & + & + & \cdot & + & \mathrm{r} & \mathrm{r} \\
1 & 1 & 2 & 1 & 1 & + & 1 & 4 & 1 & 3 & 1 & + & + & \mathrm{r} & 4 & 4 & \mathrm{r}
\end{array}\right|
$$

Д.в. класcа Isoëto-Nanojuncetea

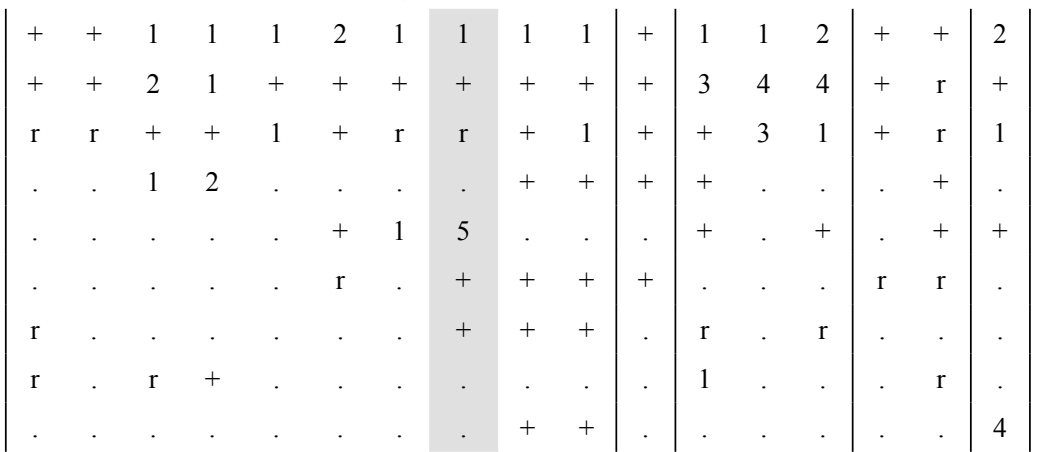

\begin{tabular}{|c|c|c|c|c|c|c|c|c|c|c|c|c|c|c|c|c|}
\hline Chenopodium rubrum $\mathrm{f}$. humile & + & + & 1 & 1 & 1 & + & + & $\mathrm{r}$ & + & + & + & $\mathrm{r}$ & + & + & 1 & 1 \\
\hline Chenopodium glaucum & $\mathrm{r}$ & $\mathrm{r}$ & 1 & $\mathrm{r}$ & + & $\mathrm{r}$ & + & $\mathrm{r}$ & 1 & 1 & + & + & 1 & + & 1 & + \\
\hline Rorippa palustris & 1 & 1 & + & + & + & + & 1 & 1 & + & 1 & + & + & 1 & $\mathrm{r}$ & $\mathrm{r}$ & 1 \\
\hline Bidens cernua & $\mathrm{r}$ & + & $\cdot$ & . & $\mathrm{r}$ & $\mathrm{r}$ & + & + & . & . & $\cdot$ & . & r & + & · & $\mathrm{r}$ \\
\hline Echinochloa crusgalli & + & $\mathrm{r}$ & + & 1 & . & . & 1 & + & + & + & . & . & $\mathrm{r}$ & + & $\cdot$ & . \\
\hline Bidens tripartita & $\mathrm{r}$ & . & . & . & . & $\mathrm{r}$ & + & + & + & $\cdot$ & . & . & $\mathrm{r}$ & $\mathrm{r}$ & $r$ & . \\
\hline Ranunculus sceleratus & $\mathrm{r}$ & $\mathrm{r}$ & . & . & . & $\mathrm{r}$ & . & + & + & + & . & . & . & . & . & $\mathrm{rj}$ \\
\hline
\end{tabular}

Д.в. класcа Salicetea purpureae 
Продолжение табл. 2

Continued Table. 2

\begin{tabular}{|l|c|c|c|c|c|c|c|c|c|c|c|c|c|c|c|c|c|}
\hline \multicolumn{1}{|c|}{ Номер описания } & 11 & 12 & 13 & 14 & 15 & 16 & 17 & 18 & 19 & 20 & 21 & 22 & 23 & 24 & 25 & 26 & 27 \\
\hline $\begin{array}{l}\text { Rumex maritimus } \\
\text { Persicaria scabra }\end{array}$ & + & $\mathrm{r}$ & $\mathrm{r}$ & $\mathrm{r}$ &. &. & $\mathrm{r}$ &. &. &. &. &. & + & + & $\mathrm{r}$ & $\mathrm{r}$ & 1 \\
&. &. &. &. &. &. & $\mathrm{r}$ & + & + &. &. & $\mathrm{r}$ & + &. &. &. &.
\end{tabular}

Eleocharis palustris

Alisma plantago-aquatica

Veronica anagallis-aquatica

Bolboschoenus maritimus

Rorippa amphibia

Lythrum salicaria

Leersia oryzoides

Carex acuta (juv.)

Typha angustifolia (imm.)

\section{Д.в. класса Phragmito-Magnocaricetea}

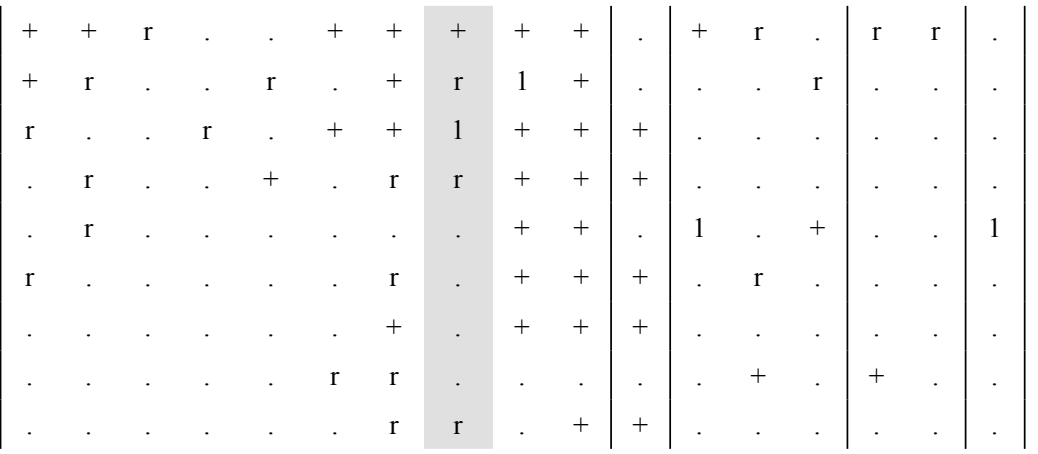

Прочие виды

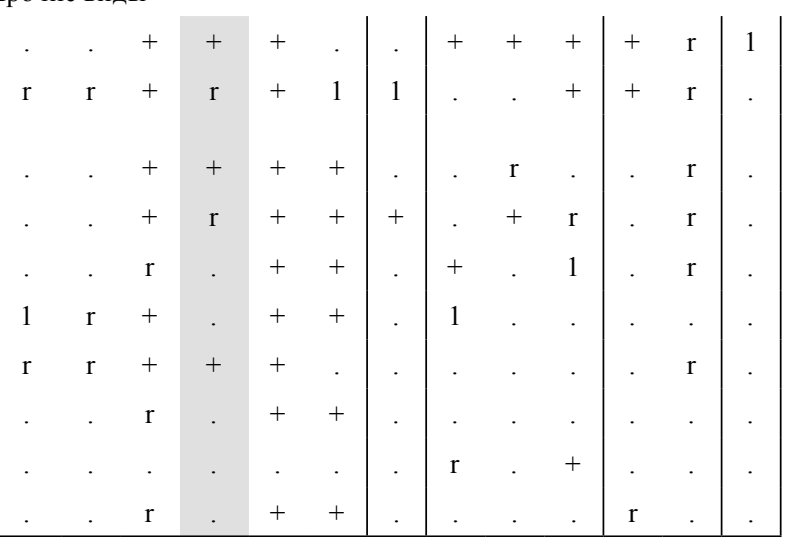

$$
\begin{array}{|cccc}
+ & + & \mathrm{r} & \cdot \\
\cdot & \cdot & + & \cdot \\
\mathrm{r} & \mathrm{r} & \mathrm{r} & \cdot \\
\cdot & \cdot & \mathrm{r} & \cdot \\
\mathrm{r} & \mathrm{r} & \cdot & \cdot \\
\mathrm{r} & 1 & \cdot & \cdot \\
\mathrm{r} & \cdot & \cdot & \cdot \\
\mathrm{r} & \mathrm{r} & \cdot & \cdot \\
\mathrm{r} & \mathrm{r} & \cdot & \cdot \\
\cdot & \cdot & \cdot & \cdot
\end{array}
$$

Agrostis stolonifera

Equisetum arvense f. prostratum

Potentilla supina ssp. paradoxa (juv.)

Juncus compressus

Lycopus exaltatus

Mentha arvensis

Juncus articulatus

Ranunculus repens

Cirsium sp. (juv.)

Rorippa sylvestris

Примечание. С невысоким постоянством отмечены: сосудистые - Acer negundo 22(rj); Agrostis gigantea 18(+), 19(+), 20(+); Alisma gramineum 19(+); Amaranthus retroflexus 19(+), 20(+); Androsace filiformis 19(+); Artemisia absinthium 19(+); Artemisia vulgaris 17(rj), 19(+); Butomus umbellatus 17(r), 19(+), 20(+); Calamagrostis epigeios 16(+), 19(+), 20(+); Calamagrostis cf. purpurea 17(r); Cardamine parviflora 19(+); Carduus crispus 17(rj); Carex bohemica 26(r); Carex riparia 21(+); Chenopodium album 16(r); Cicuta virosa 17(r); Cirsium incanum 25(r); Cirsium setosum $19(+\mathrm{j})$, 25(rj); Conyza canadensis 19(+), 20(+); Convolvulus arvensis 20(+); Crypsis schoenoides 13(+); Epilobium ciliatum 18(r); Erysimum cheiranthoides 17(+); Filipendula vulgaris 20(+); Galium palustre 17(r); Galium uliginosum 19(+); Gratiola officinalis 12(+); Halerpestes sarmentosa 19(+); Herniaria polygama 17(r); Hypericum perforatum 21(+); Inula britannica 17(+), 19(+), 20(+); Juncus alpinoarticulatus 20(+), 21(+); Juncus ambiguus 15(r); Juncus bufonius 17(+), 18(+), 23(r); Kochia sp. 25(r); Lysimachia vulgaris 11(rj), 19(+j); Myosotis caespitosa 16(r); Myosoton aquaticum 17(r); Myriophyllum verticillatum 20(+); Persicaria hydropiper 22(r); Phalaroides arundinacea 19(+); Potentilla anserina 18(r); Potentilla norvegica 20(+); Psammophiliella muralis 17(r); Rumex aquaticus 17(r); Rumex sp. 23(rj); Rumex ucranicus 16(r); Sagittaria sagittifolia 18(+), 20(+); Salix viminalis 25(rj); Scirpus radicans 14(r); Sonchus arvensis 17(rj), 19(+j), 20(+j); Spergularia diandra 14(r), 16(r); Stachys palustris 19(+), 20(+); Tanacetum vulgare $21(+\mathrm{j})$; Taraxacum officinale $17(\mathrm{rj})$; Thalictrum minus 20(+j); Tripleurospermum perforatum $19(+) ;$ Typha latifolia 19(+); Verbascum thapsus 19(+); Veronica longifolia 19(+), 20(+), 26(rj); мохообразные - D Bryum argenteum 17(+); D Marchantia alpestris 17(r). Условные знаки: * - для низких значений ОПП в табл. 2-4 вместо процентов используются баллы: «r»- ОПП не более $0,01 \%$, «+»- ОПП более 0,01 , но менее $0,3 \% ; 77^{+}, 87^{+}$означает более 77 , более 87 ; «-»нет данных; D - напочвенный ярус; «juv.» - всходы; «ітm.» - имматурные экземпляры. Адреса и даты описаний. Все описания сделаны в Алтайском крае. Первомайский р-н, окр. с. Бобровка, пойма Оби: 11-13 - оп. 597, 598, 601, 26.08.1992; 14-15 - оп. 605, 606, 27.08.1992; 16 - оп. 610, 30.08.1992; 17-18 - оп. 617, 618, 03.09.1992. Быстроистокский р-н, окр. с. Быстрый Исток, р. Обь, о-в Сосновый: 19 - оп. 12, 23.08.2007; 20 - оп. 13, 24.08.2007; 21 - оп. 9, 19.08.2007. Первомайский р-н, окр. с. Бобровка, пойма Оби: 22 - оп. 596, 26.08.1992; 23 - оп. 607, 28.08.1992; 24 - оп. 612, 30.08.1992; 25 - оп. 604, 27.08.1992; 26 - оп. 609, 30.08.1992; 27 - оп. 611, 30.08.1992. 
Таблица 3. Субасс. Cypero fusci-Limoselletum aquaticae riccietosum frostii; фации limosellosum aquaticae (28-39) и eleocharitosum acicularis (40-48); acc. Peplido alternifoliae-Alismatetum graminei, вар. Cyperus fuscus, фация eleocharitosum acicularis (49)

Table 3. Subass. Cypero fusci-Limoselletum aquaticae riccietosum frostii; facies limosellosum aquaticae (28-39) and eleocharitosum acicularis (40-48); ass. Peplido alternifoliae-Alismatetum graminei, var. Cyperus fuscus, facies eleocharitosum acicularis (49)

\begin{tabular}{|c|c|c|c|c|c|c|c|c|c|c|c|c|c|c|c|c|c|c|c|c|c|c|}
\hline Номер описания & 28 & 29 & 30 & 31 & 32 & 33 & 34 & 35 & 36 & 37 & 38 & 39 & 40 & 41 & 42 & 43 & 44 & 45 & 46 & 47 & 48 & 49 \\
\hline Плог & 10 & 10 & 10 & 10 & 2 & 7 & 1 & 3 & 2 & 4 & 6 & 10 & 1 & 4 & 10 & 2 & 2 & 2 & 4 & 7 & 6 & 2 \\
\hline Высо & 1.5 & 1,5 & 1 & 2 & 2 & 5 & 2 & 2 & 2 & 2 & 2 & 2 & 3 & 3 & 3 & 4 & 3 & 3 & 2 & 4 & 4 & 4 \\
\hline ОПП Salicaceae, \% & + & + & + & $\mathrm{r}$ & + & 1 & 1 & $\mathrm{r}$ & 0 & $\mathrm{r}$ & $\mathrm{r}$ & 5 & + & $\mathrm{r}$ & $\mathrm{r}$ & $\mathrm{r}$ & + & + & $\mathrm{r}$ & 1 & 1 & 0 \\
\hline ОПП травостоя & 50 & 50 & 40 & 40 & 60 & 35 & 25 & 25 & 50 & 40 & 25 & 60 & 70 & 50 & 40 & 40 & 40 & 40 & 70 & 25 & 25 & 40 \\
\hline ОПП мохоо & $\mathrm{r}$ & + & 1 & + & + & 5 & + & 0 & 0 & $\mathrm{r}$ & $\mathrm{r}$ & $\mathrm{r}$ & 0 & 0 & + & 0 & $\mathrm{r}$ & $\mathrm{r}$ & + & 1 & + & 0,5 \\
\hline ПП Botrydium, \% & 0 & 0 & 0 & 0 & 0 & 90 & + & 0 & + & 1 & + & $\mathrm{r}$ & 0 & 0 & 0 & 0 & 0 & 0 & 0 & + & $r$ & + \\
\hline & 28 & 29 & 25 & 34 & 23 & 31 & 12 & 11 & 14 & 17 & 27 & 28 & 7 & 16 & 24 & 13 & 14 & 10 & 12 & 27 & 23 & 21 \\
\hline $\begin{array}{l}\text { Числ } \\
\text { мохо }\end{array}$ & 1 & 1 & 1 & 2 & 2 & 2 & 2 & 0 & 0 & 1 & 2 & 1 & 0 & 0 & 1 & 0 & 1 & 1 & 1 & 3 & 2 & 1 \\
\hline Толщина ила, см & - & - & 27 & 19 & - & - & \multicolumn{5}{|c|}{ более 25} & - & - & - & - & - & - & - & - & - & - & - \\
\hline УГВ, см & - & - & 72 & 69 & - & 2 & 15 & 8 & 15 & 15 & 15 & - & - & - & - & - & - & - & - & - & - & - \\
\hline
\end{tabular}

Д.в. асс. Cypero-Limoselletum и субасс. C.-L. riccietosum frostii

\begin{tabular}{l|ccccccccccccc|cccccccccc|c|} 
Limosella aquatica & 4 & 4 & 4 & 4 & 4 & 3 & 3 & 3 & 4 & 4 & 3 & 4 & 2 & + & + & + & + & + & + & 1 & + & 1 \\
Cyperus fuscus & + & 1 & + & 1 & 1 & 2 & + & + & 1 & + & 1 & 1 &. &. & + & $\mathrm{r}$ & $\mathrm{r}$ & + & $\mathrm{r}$ & + & $\mathrm{r}$ & + \\
D Riccia frostii & $\mathrm{r}$ & + & 1 & + & + & 1 & + &. &. &. & $\mathrm{r}$ &. &. &. & + &. & $\mathrm{r}$ & $\mathrm{r}$ & + & 1 & + & +
\end{tabular}

Д.в. класса Isoëto-Nanojuncetea

Filaginella rossica

Eleocharis acicularis

Plantago intermedia

D Botrydium granulatum

D Physcomitrella patens

D Riccia cavernosa

Rorippa palustris

Bidens tripartita

Bidens cernua

Chenopodium rubrum

Chenopodium glaucum

Echinochloa crusgalli

Rumex maritimus

Ranunculus sceleratus

Persicaria scabra

Д.в. класса Phragmito-Magnocaricetea

Eleocharis palustris

Rorippa amphibia

Alisma plantago-aquatica

Carex acuta (juv.)

\section{Д.в. класcа Bidentetea}

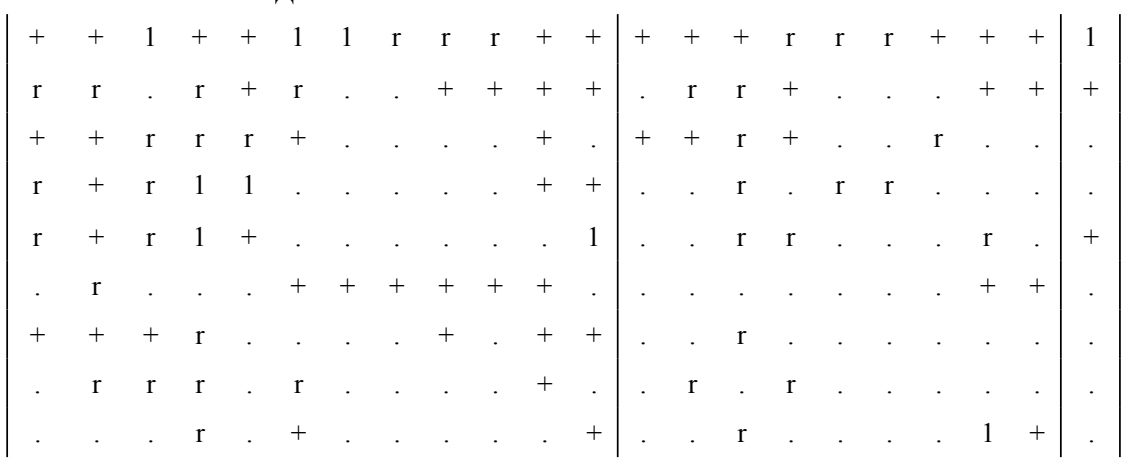

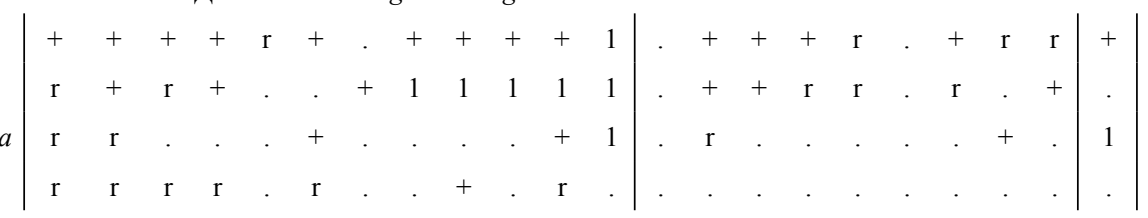


Продолжение табл. 3

Continued Table. 3

\begin{tabular}{|c|c|c|c|c|c|c|c|c|c|c|c|c|c|c|c|c|c|c|c|c|c|c|}
\hline Номер описания & 28 & 29 & 30 & 31 & 32 & 33 & 34 & 35 & 36 & 37 & 38 & 39 & 40 & 41 & 42 & 43 & 44 & 45 & 46 & 47 & 48 & 49 \\
\hline $\begin{array}{l}\text { Bolboschoenus } \\
\text { maritimus }\end{array}$ & + & $\mathrm{r}$ & $+\mathrm{j}$ & + & • & $\mathrm{r}$ & - & . & . & ${ }^{\circ}$ & - & . & + & . & + & . & . & . & $\cdot$ & - & . & . \\
\hline Typha angustifolia (juv.) & . & . & . & & . & + & . & + & + & r & + & $\mathrm{r}$ & . & . & . & . & 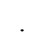 & . & . & . & . & + \\
\hline
\end{tabular}

Д.в. класcа Salicetea purpureaew

\begin{tabular}{|c|c|c|c|c|c|c|c|c|c|c|c|c|c|c|c|c|c|c|c|c|c|c|}
\hline Salix alba (juv.) & + & + & $\mathrm{r}$ & $\mathrm{r}$ & + & + & + & $\mathrm{r}$ & . & $\mathrm{r}$ & $\mathrm{r}$ & + & $\cdot$ & $\mathrm{r}$ & $\mathrm{r}$ & $\mathrm{r}$ & + & + & $\mathrm{r}$ & $\cdot$ & . & . \\
\hline Salix triandra (juv.) & + & + & + & . & . & + & + & $\cdot$ & $\cdot$ & $\mathrm{r}$ & $\mathrm{r}$ & 1 & + & $\mathrm{r}$ & $\mathrm{r}$ & . & $\mathrm{r}$ & r & . & $\cdot$ & $\cdot$ & $\cdot$ \\
\hline \multicolumn{23}{|c|}{ Прочие виды } \\
\hline Agrostis stolonifera & + & $\mathrm{r}$ & $\mathrm{r}$ & $\mathrm{r}$ & . & + & . & + & . & + & . & 1 & . & $\mathrm{r}$ & $\mathrm{r}$ & . & . & . & . & $\mathrm{r}$ & $\mathrm{r}$ & + \\
\hline Mentha arvensis & + & + & + & $\mathrm{r}$ & $r$ & . & $+\mathrm{j}$ & . & . & . & $\mathrm{rj}$ & . & . & $\mathrm{r}$ & + & . & . & . & $\mathrm{r}$ & $\mathrm{rj}$ & . & . \\
\hline $\begin{array}{l}\text { Equisetum arvense } \\
\text { f. prostratum }\end{array}$ & . & $\cdot$ & + & + & $\mathrm{r}$ & . & . & . & 1 & . & . & . & . & + & 1 & + & + & + & . & . & . & . \\
\hline $\begin{array}{l}\text { Potentilla supina } \\
\text { ssp. paradoxa }\end{array}$ & $\mathrm{r}$ & $\mathrm{r}$ & $\mathrm{r}$ & $\mathrm{r}$ & . & $\mathrm{r}$ & + & . & . & $\mathrm{r}$ & + & . & . & . & . & . & $\mathrm{r}$ & . & . & . & . & . \\
\hline Potamogeton gramineus & . & $\cdot$ & . & . & . & . & . & 1 & + & + & + & . & $\cdot$ & . & . & . & . & . & . & . & . & + \\
\hline Cirsium sp. (juv.) & . & $\mathrm{r}$ & . & $\mathrm{r}$ & $\mathrm{r}$ & $\mathrm{r}$ & . & . & . & . & . & . & . & . & $\mathrm{r}$ & . & . & . & . & . & . & . \\
\hline Juncus articulatus & $\mathrm{r}$ & . & . & $\mathrm{r}$ & $r$ & $\mathrm{r}$ & + & . & . & . & . & . & . & . & . & . & . & . & . & . & . & . \\
\hline
\end{tabular}

Примечание. С невысоким постоянством отмечены: Agrostis gigantea 28(r), 28(r), 32(r); Alisma gramineum 39(1), 49(1); Amoria repens 47(r); Artemisia sieversiana 47(rj), 48(rj); Batrachium rionii 47(+); Bidens radiata 38(+), 39(1); Butomus umbellatus 39(1), 46(r), 48(+); Calamagrostis epigeios 31(r); Callitriche palustris 49(1); Carduus crispus 47(+j), 48(rj); Chenopodium album 42(r); Dichostylis micheliana 31(+), 33(r), 38(+); Elatine hydropiper 47(+), 48(+); Epilobium ciliatum 33(r); Equisetum fluviatile 36(+), 37(+), 38(+), 42(r); Eragrostis amurensis 30(r), 31(+), 32(+); Fagopyrum tataricum 28(rj); Festuca pratensis (imm.) 42(r), 44(r); Halerpestes sarmentosa 33(r); Hippuris vulgaris 39(1); Juncus bufonius 33(r), 39(+), 48(r); Juncus compressus 31(+), 32(+), 33(r), 39(+); Inula britannica 29(r), 49(+); Lindernia procumbens 31(r); Lycopus exaltatus 29(r), 31(r); Lysimachia vulgaris 34(+); Lythrum salicaria 32(rj); Lythrum sp. 48(+j); Middendorfia borysthenica 49(+); Myosotis cespitosa 47(r); Naumburgia thyrsiflora 30(r); Persicaria amphibia 35(+), 37(+), 38(+); Persicaria hydropiper 32(r), 48(+), 49(1); Polygonum aviculare aggr. 39(r); Polygonum arenastrum 49(+); Populus laurifolia 47(+j), 48(+j); Populus nigra 47(1j), 48(1j); Potentilla anserina 31(r), 49(+); Potentilla norvegica 33(r), 39(+), 47(rj), 48(rj); Ptarmica cartilaginea 30(r), 33(r); Ranunculus repens 28(rj), 38(+); Rorippa sylvestris 47(r), 48(r); Rumex aquaticus 33(r); Rumex ucranicus 28(r); Sagittaria natans 47(+), 48(+); Salix pyrolifolia 29(rj); Salix viminalis 31(rj); Scirpus supinus 49(+); Sonchus arvensis 31(rj), 47(rj); Sparganium emersum 28(r), 29(r), 47(+); Spergularia diandra 31(r); Spirodela polyrhiza 38(+); Typha latifolia 34(+j), 37(+j), 39(rj); Veronica anagallis-aquatica 31(r), 33(+), 39(+); Veronica longifolia 32(rj). Условные знаки: УГВ - уровень грунтовых вод; «-»-нет данных. Адреса, полевые номера и даты описаний. Алтайский край, Первомайский р-н, окр. с. Бобровка, пойма Оби: 28-30 - оп. 586, 587, 594, 25.08.1992; 31-32 - оп. 602, 603, 26.08.1992; 33 - оп. 624, 04.09 .1992$. Новосибирская обл., Сузунский р-н, окр. с. Верхний Сузун, берег Оби в устье р. Верхний Сузун: 34-38 - оп. 724-728, 07.09.1994. Новосибирская обл., Колыванский р-н, с. Колывань, 2 км на северо-восток, пойма Оби, берег р. Чаус: 39 оп. 464, 06.08.1991. Алтайский край, Первомайский р-н, окр. с. Бобровка, пойма Оби: 40-45 - оп. 588-593, 25.08.1992; 46 - оп. 595, 26.08.1992. Алтайский край, Бийский р-н, окр. с. Стан-Бехтемир, р. Бия, остров к востоку от села: 47-48 оп. 710, 711, 25.08.1994. Новосибирская обл., Сузунский р-н, с. Мереть, берег протоки: 49 - оп. 789, 08.09.1996.

Limoselletum в иерархии высших синтаксонов таково: союз Eleocharition soloniensis Philippi 1968, порядок Nanocyperetalia Klika 1935, класс Isoëto-Nanojuncetea Br.-Bl. et Tx. in Br.-Bl. et al. 1952.

Ареал ассоциации охватывает зарубежную Европу (Korneck, 1960; Oesau, 1972; Pietsch, 1973; Philippi, 1992; Rašomavičius,
Biveinis, 1996; Täuber, 2000; Коваленко, 2014), европейскую часть России (Соломещ, Гаврилов, 1989; Аверинова, 2010) и Западную Сибирь (Киприянова, 2008).

Ценозы acc. Cypero-Limoselletum, pacпространенные на лесостепном отрезке Оби, обладают региональной спецификой. В них имеются виды, которые в Центральной Евро- 
пе редки (Riccia frostii, Eragrostis amurensis) и в тамошних описаниях не указывались. На этом основании верхнеобские сообщества я выделяю в качестве новой субассоциации: Cypero fusci-Limoselletum aquaticae riccietosum frostii subass. nov. hoc loco. Hoменклатурный тип (holotypus) - оп. 18 в табл. 2: полевой номер 618, 03.09.1992, Алтайский край, Первомайский р-н, пойма Оби у с. Бобровка, прирусловая отмель на протоке, отделяющей остров Невестинский от коренного берега ниже впадения в нее р. Бобровки; Г.С. Таран. Диагностический вид субассоциации: Riccia frostii.

Основываясь на доминировании отдельных видов, описания ассоциации можно разделить на ряд фаций. В частности, в лесостепи в составе acc. Cypero-Limoselletum широко представлена фация cyperosum fusci (оп. 11-20). Сходные сообщества для р. Берди указывает Л.М. Киприянова (2008).

Фация salicosum albae образована сеянцами ветлы. В оп. 21 их высота 8 см. Ценозы, образованные сеянцами ив, на следующий год чаще всего погибают, повреждаясь весенним ледоходом, смываясь полыми водами, погребаясь новыми слоями аллювия. Иначе говоря, они однолетние «по принуждению» (Таран, 1995). В благоприятных условиях сеянцы ив продолжают развитие, формируя новые поколения аллювиальных ивняков. Поэтому фацию salicosum albae можно рассматривать и как стадию заселения ветловых лесов.

Ранее (Таран, 2015) из поймы верхней Оби охарактеризованы ивняки из сеянцев Salix triandra. Они могут оцениваться и как стадия заселения ивовых лесов (acc. Salicetum triandro-viminalis Lohm. 1952), и как фация salicosum triandrae в составе асc. CyperoLimoselletum и Eleocharito ovatae-Caricetum bohemicae Klika 1935 (для ценозов с участием Eleocharis ovata).
Фация filaginellosum rossicae на верхней Оби, вероятно, довольно обычна, но удалось сделать лишь три описания (оп. 22-24). Эти ценозы отмечены на верхних уровнях пояса прирусловых эфемеров.

Сообщества фации ricciosum frostii (оп. 25-26) размещались на обсохших в межень подвальях русловых микрогряд, покрывавших тела крупных обских побочней. Массовому развитию риччий на этих обширных песчаных пространствах благоприятствует малое количество диаспор сосудистых растений в сочетании с поздними сроками освобождения побочней от воды.

Наиболее редка фация linderniosum procumbentis (оп. 27). Она отмечена в новейшей прирусловой зоне Оби, поверхность которой была покрыта пестрой смесью из латок однолетних и многолетних травэксплерентов и лент ювенильных ивняков. В лесостепной зоне линдерниевая фация занимает экстразональное положение. Ее основной ареал в Обь-Иртышском бассейне - полупустынный отрезок поймы Черного Иртыша (Таран, 1993).

Фация limosellosum aquaticae обнаружена в центральной лесостепи, у сел Бобровка (оп. 28-33) и Верхний Сузун (оп. 3438), и в северной лесостепи, у с. Колывань (оп. 39).

Фация eleocharitosum acicularis характерна для илистых грунтов. Она наблюдалась в центральной лесостепи, у с. Бобровка (оп. 40-46), и в предгорной степи, у с. СтанБехтемир (оп. 47-48).

Оп. 49, включающее Scirpus supinus, Alisma gramineum, Middendorfia borysthenica, Polygonum arenastrum, сделано на дне сырого замкнутого понижения (высохшей лужи), располагавшейся на илистом берегу внутрипойменной протоки. Окружали понижение сырые и болотистые луга с преобладанием 
Persicaria hydropiper, Agrostis stolonifera, Potentilla anserina, Eleocharis acicularis, Eleocharis palustris. Этот ценоз относится к acc. Peplido-Alismatetum graminei, вар. Cyperus fuscus.

Материалы по пойменному эфемеретуму верхней Оби и нижней Бии, изложенные в данной статье и опубликованные ранее (Таран, 1995, 2015), подытожены в табл. 4.

\section{Заключение}

Пойменный эфемеретум лесостепного отрезка р. Оби и нижнего течения р. Бии представлен тремя ассоциациями из двух союзов порядка Nanocyperetalia Klika 1935 и класcа Isoëto-Nanojuncetea Br.-Bl. et Tx. in Br.-Bl. et al. 1952.

На грунтовых дорогах высоких уровней поймы в годы сильных половодий появляются сообщества «дорожного» эфемеретума, описанные в данной статье как acc. Peplido alternifoliae-Alismatetum graminei ass. nov. (союз Nanocyperion Koch 1926). В составе ассоциации отмечены редкие в Западной Сибири виды: Lindernia procumbens, Scirpus supinus, Peplis alternifolia, Middendorfia borysthenica. Cyбacc. Cypero-Limoselletum scirpetosum lateriflori Taran 1995 перенесена в acc. Peplido alternifoliae-Alismatetum graminei в качестве варианта Cyperus fuscus. Местонахождения ассоциации выявлены в пойме Оби в трех точках: окрестности сел Мереть и Верхний Сузун (Сузунский р-н Новосибирской обла- сти), берег протоки Заломной (Каменский р-н Алтайского края) в 18 км на запад от с. Верхний Сузун.

На меженных отмелях верхней Оби преобладает acc. Cypero fusci-Limoselletum aquaticae (Oberd. 1957) Korneck 1960 (союз Eleocharition soloniensis Philippi 1968), представленная субассоциацией Cypero fusciLimoselletum aquaticae riccietosum frostii subass. nov. Изредка ее сообщества отмечаются в низовьях Бии.

Субасc. Eleocharito ovatae-Caricetum bohemicae gnaphalietosum rossici Taran 1995 (союз Eleocharition soloniensis), доминирующая на отмелях нижней Бии, отличается от прочих обских синтаксонов класса IsoёtoNanojuncetea наличием Eleocharis ovata и высокой видовой насыщенностью.

\section{Благодарности}

Благодарю М.М. Силантьеву (АлтГУ, г. Барнаул) за помощь в организации исследований в пойме верхней Оби, В.А. Бакалина (БСИ ДВО РАН, г. Владивосток) - за определение сборов риччий из пойм ОбьИртышского бассейна, М.Н. Ломоносову и В.В. Зуева (ЦСБС СО РАН, г. Новосибирск), Н.Н. Тупицыну (Красноярский гос. пед. унт, г. Красноярск) и Eisuke Hayasaka (Tohoku University, Sendai, Japan) - за определение отдельных видов сосудистых, В.Н. Тюрина (СурГУ, г. Сургут) - за подготовку рисунка к статье. 
Таблица 4. Пойменный эфемеретум лесостепного отрезка р. Оби и низовьев р. Бии (указаны, главным образом, виды, отмеченные с III-V классами постоянства)

Table 4. Ephemeral wetland vegetation of the Ob River forest-steppe course and the Biya River lower course (species recorded with III-V constancy classes are mainly indicated)

\begin{tabular}{|c|c|c|c|c|c|c|c|c|}
\hline Номер столбца & 1 & 2 & 3 & 4 & 5 & 6 & 7 & 8 \\
\hline Ассоциация & E.-C. & \multicolumn{5}{|c|}{ Cypero-Limoselletum } & \multicolumn{2}{|c|}{ P.a.-A.g. } \\
\hline Субассоциация & filag. & \multicolumn{5}{|c|}{ riccietosum frostii } & \multicolumn{2}{|c|}{ typicum } \\
\hline Вариант, фация (...) & typ. & (c.f.) & (1.a.) & (div.) & (sal.) & (e.a.) & C.f. & typ. \\
\hline Число описаний & 11 & 10 & 12 & 6 & 6 & 9 & 9 & 10 \\
\hline Средняя площадь описания, м² & 8,5 & 6,2 & 6,2 & 4,7 & 8,9 & 4,2 & 3,6 & 1,3 \\
\hline Среднее ОПП Salicaceae, \% & 4 & 0,3 & 0,6 & + & 37 & + & + & + \\
\hline Среднее ОПП травостоя, \% & 32 & 49 & 41 & 30 & 7 & 44 & 49 & 48 \\
\hline Среднее ОПП мохообразных, \% & 1 & 8 & 0,5 & 17 & 2 & 0,3 & + & $\mathrm{r}$ \\
\hline Среднее ПП Botrydium granulatum, \% & 6 & 6 & 8 & + & 16 & + & + & 0 \\
\hline Среднее число видов сосудистых & 42,2 & 29,8 & 23,2 & 19,0 & 21,0 & 16,2 & 20,6 & 20,9 \\
\hline Общее число видов сосудистых & 117 & 88 & 67 & 44 & 53 & 45 & 44 & 62 \\
\hline Общее число видов низших растений & 8 & 6 & 4 & 4 & 4 & 4 & 4 & 2 \\
\hline
\end{tabular}

Д.в. асc. Eleocharito-Caricetum bohemicae и субасс. E.-C.b. filaginelletosum rossicae

Eleocharis ovata

Androsace filiformis

$\mathrm{V}^{+1}$
III

Д.в. асc. Cypero-Limoselletum и субасс. C.-L. riccietosum frostii

Limosella aquatica

Cyperus fuscus

D Riccia frostii

\begin{tabular}{|c|cccc}
$\mathrm{V}^{+1}$ & $\mathrm{~V}$ & $\mathrm{~V}^{34}$ & $\mathrm{~V}$ & $\mathrm{~V}$ \\
$\mathrm{~V}^{13}$ & $\mathrm{~V}^{44}$ & $\mathrm{~V}^{+1}$ & $\mathrm{~V}^{+1}$ & $\mathrm{~V}^{+1}$ \\
$\mathrm{~V}^{\mathrm{r} 1}$ & $\mathrm{~V}^{12}$ & $\mathrm{IV}$ & $\mathrm{V}^{\mathrm{r} 4}$ & $\mathrm{~V}^{11}$
\end{tabular}

\begin{tabular}{c|cc}
$\mathrm{V}$ & $\mathrm{V}^{12}$ & $\mathrm{~V}^{+2}$ \\
$\mathrm{IV}$ & $\mathrm{III}$ & $\cdot$ \\
$\mathrm{IV}$ & $\mathrm{III}$ & +
\end{tabular}

Д.в. acc. Peplido alternifoliae-Alismatetum graminei

Alisma gramineum (loc.)

Polygonum aviculare aggr. (loc.)

Scirpus supinus

Lindernia procumbens

Filaginella rossica

Plantago intermedia

Eleocharis acicularis f. annua

D Physcomitrella patens

D Botrydium granulatum

Eragrostis amurensis

Juncus bufonius

D Riccia cavernosa

Dichostylis micheliana

Peplis alternifolia

Alisma bjoerkqvistii

Salix alba (juv.)

Populus nigra (juv.)

Salix triandra (juv.)

Salix viminalis (juv.)

Rorippa palustris

\begin{tabular}{|c|c} 
I & + \\
$\cdot$ & $\cdot$ \\
$\cdot$ & $\cdot$ \\
II & I
\end{tabular}

Д.в. класса Isoëto-Nanojuncetea

$$
\begin{array}{|c|ccccc|cc|}
\text { V } & \text { V } & \text { V } & \mathrm{V}^{+4} & \text { V } & \text { V } & \text { I } & \text { I } \\
\mathrm{V}^{11} & \mathrm{~V}^{11} & \text { IV }^{-1} & \mathrm{~V}^{+2} & \text { V } & \text { IV } & \text { I } & \cdot \\
\text { V } & \text { II } & \text { III } & \text { II } & \text { III } & \text { V }^{44} & \text { II } & \cdot \\
\text { III } & \text { V } & \text { II } & \mathrm{V}^{+1} & \text { I } & \text { II } & \text { III } & \cdot \\
\text { IV } & \text { II } & \text { III } & \text { IV } & \text { II } & \text { II } & \text { II } & \cdot \\
\text { V } & \text { II } & \text { II } & \text { II } & \text { III } & \cdot & \cdot & \cdot \\
\text { V } & \text { II } & \text { I } & \text { I } & \text { III } & \text { I } & \cdot & \cdot \\
\text { I } & \text { II } & \text { II } & \text { II } & \text { II } & \text { I } & \text { III } & + \\
\text { I } & \text { II } & \text { II } & \text { II } & \text { II } & \cdot & \cdot & \cdot \\
\cdot & \cdot & \cdot & \cdot & \cdot & \cdot & \text { II } & \text { III } \\
\cdot & \cdot & \cdot & \cdot & \cdot & \cdot & \cdot & \text { II }
\end{array}
$$

Д.в. класcа Salicetea purpureae

$$
\begin{array}{|c|ccccc|cc|}
\mathrm{V}^{\mathrm{rl}} & \mathrm{IV} & \mathrm{V} & \mathrm{V} & \mathrm{IV} & \mathrm{IV} & \mathrm{III} & + \\
\mathrm{V} & + & . & \text { III } & \text { I } & \text { II } & \text { IV } & \text { I } \\
\text { II } & \text { II } & \text { IV } & \text { I } & \mathrm{V}^{45} & \text { III } & \cdot & \cdot \\
\text { III } & \cdot & + & \text { I } & \text { II } & . & \cdot & .
\end{array}
$$

Д.в. класcа Bidentetea

\begin{tabular}{|l|lllll|ll}
$\mathrm{V}^{+1}$ & $\mathrm{~V}^{+1}$ & $\mathrm{~V}$ & $\mathrm{~V}^{\mathrm{r} 1}$ & $\mathrm{~V}$ & $\mathrm{~V}$ & $\mathrm{IV}$ & $\mathrm{IV}$
\end{tabular} \mid


Продолжение табл. 4

Continued Table. 4

\begin{tabular}{|c|c|c|c|c|c|c|c|c|}
\hline Номер столбца & 1 & 2 & 3 & 4 & 5 & 6 & 7 & 8 \\
\hline Chenopodium glaucum f. humile & V & $\mathrm{V}^{\mathrm{r} 1}$ & III & $\mathrm{V}^{+1}$ & IV & II & I & II \\
\hline Bidens tripartita & IV & III & IV & III & III & III & IV & . \\
\hline Chenopodium rubrum $\mathrm{f}$. humile & III & $\mathrm{V}^{+1}$ & III & $\mathrm{V}^{+1}$ & III & II & $\cdot$ & . \\
\hline Bidens cernua & II & III & III & II & II & III & I & . \\
\hline Ranunculus sceleratus & III & III & III & I & II & II & III & . \\
\hline Rumex maritimus & $\mathrm{I}$ & III & III & $\mathrm{V}$ & I & I & . & . \\
\hline Persicaria scabra & II & II & II & II & III & II & . & . \\
\hline Persicaria lapathifolia & $\mathrm{IV}^{+1}$ & . & $\cdot$ & . & . & . & . & . \\
\hline Persicaria minor & . & . & . & . & . & . & IV & I \\
\hline
\end{tabular}

Eleocharis palustris

Alisma plantago-aquatica

Veronica anagallis-aquatica

Juncus compressus

Rorippa amphibia

Typha angustifolia

Juncus articulatus

Bolboschoenus maritimus

Carex acuta

Butomus umbellatus

Leersia oryzoides

Lythrum salicaria

Lythrum virgatum

Veronica beccabunga

\begin{tabular}{|c|c|c|c|c|c|c|c|}
\hline $\mathrm{V}$ & IV & V & IV & IV & IV & $\mathrm{V}$ & IV \\
\hline IV & IV & III & I & II & II & $\mathrm{V}^{11}$ & $\mathrm{~V}^{+1}$ \\
\hline $\mathrm{V}$ & IV & II & . & IV & . & $\mathrm{V}^{11}$ & $\mathrm{IV}^{-1}$ \\
\hline $\mathrm{V}$ & III & II & III & II & . & IV & $\mathrm{IV}^{+1}$ \\
\hline II & II & $\mathrm{V}^{\mathrm{r} 1}$ & $\mathrm{III}^{-1}$ & II & IV & . & . \\
\hline II & II & III & . & IV & . & IV & + \\
\hline $\mathrm{V}$ & III & III & I & I & . & . & I \\
\hline II & III & III & . & III & II & . & + \\
\hline II & I & III & II & I & . & . & + \\
\hline III & II & + & . & II & II & I & . \\
\hline IV & II & . & . & II & . & . & . \\
\hline+ & II & + & I & I & . & III & . \\
\hline II & . & . & . & . & . & . & IV \\
\hline III & . & . & . & . & . & . & . \\
\hline
\end{tabular}

Agrostis stolonifera

Echinochloa crusgalli

Equisetum arvense

Potentilla supina ssp. paradoxa

Mentha arvensis

Callitriche palustris

Rorippa sylvestris

Plantago major

Lycopus exaltatus

Ranunculus repens

Inula britannica

Agrostis gigantea

Sonchus arvensis (juv.)

Potentilla anserina

Tripleurospermum perforatum

Прочие виды

\begin{tabular}{|c|c|c|c|c|c|c|c|}
\hline IV & III & IV & $\mathrm{V}$ & III & III & V & + \\
\hline $\mathrm{V}$ & $\mathrm{V}$ & III & II & II & II & IV & $\mathrm{IV}^{+1}$ \\
\hline II & IV & II & III & III & III & II & III \\
\hline IV & IV & IV & II & II & I & . & + \\
\hline IV & IV & III & I & I & III & I & . \\
\hline IV & . & . & . & . & . & $\mathrm{V}^{34}$ & $\mathrm{~V}$ \\
\hline IV & II & . & I & I & II & . & . \\
\hline . & . & . & . & . & . & IV & $\mathrm{V}^{+1}$ \\
\hline II & III & I & III & . & . & . & . \\
\hline IV & III & I & . & . & . & . & I \\
\hline IV & II & + & . & . & . & II & II \\
\hline I & II & II & . & II & . & I & III \\
\hline III & II & + & . & . & I & . & + \\
\hline I & I & + & . & I & . & III & + \\
\hline III & I & . & . & I &. & . & . \\
\hline
\end{tabular}

Названия синтаксонов: 1 - Eleocharito-Caricetum bohemicae filaginelletosum rossicae (Таран, 1995: 10 оп.; Таран, 2015: 1 оп.); 2-6 - Cypero fusci-Limoselletum aquaticae riccietosum frostii subass. nov. (Таран, 2015: 5 оп., данная статья: 38 оп.); 7 - Peplido alternifoliae-Alismatetum graminei typicum, var. Cyperus fuscus (Таран, 1995: 8 оп.; данная статья: 1 оп.); 8 - Peplido alternifoliae-Alismatetum graminei typicum, var. typicum (данная статья: 10 оп.). Названия фаций: с.f. cyperosum fusci; 1.a. - limosellosum aquaticae; div. - filaginellosum rossicae + ricciosum frostii + linderniosum procumbentis; sal. - salicosum triandrae (Таран, 2015: 5 оп.) + salicosum albae (данная статья: 1 оп.); е.а. - eleocharitosum acicularis. Классы постоянства - см. примечания к табл. 1. 


\section{Список литературы}

Аверинова Е.А. (2010) Травяная растительность бассейна реки Сейм (в пределах Курской области). Брянск, РИО БГУ, 351 с. [Averinova Е.А. (2010) Herbaceous vegetation of the Seym River basin (within the limits of Kursk Region). Bryansk, RIO BGU, 351 p. (in Russian)]

Бакалин В.А., Таран Г.С. (2004) Род Riccia (Hepaticae) в Сибири и Восточном Казахстане. Ботанический журнал, 89(8): 1283-1294 [Bakalin V.A., Taran G.S. (2004) The genus Riccia (Hepaticae) in Siberia and the East Kazakhstan. Bot. Zhurn., 89(8): 1283-1294 (in Russian)]

Горчаковский П.Л., Пешкова Н.В. (1970) Ранние стадии сукцессий растительности на новейшем аллювии в среднем течении р. Урал. Экология, 1(5): 3-15 [Gorchakovskii P.L., Peshkova N.V. (1970) Early stages of plant succession on recent alluvium in the middle course of the Ural River. Ecology [Ekologiya], 1(5): 3-15 (in Russian)]

Зверев А.А. (2007) Информационные технологии в исследованиях растительного покрова. Томск, ТМЛ-Пресс, 304 с. [Zverev А.А. (2007) Information technologies in investigations of vegetation cover. Tomsk, TML-Press, 304 p. (in Russian)]

Ильина И.С., Лапшина Е.И., Лавренко Н.Н., Мельцер Л.И., Романова Е.А., Богоявленский Б.А., Махно В.Д. (1985) Растительный покров Западно-Сибирской равнины. Новосибирск, Наука, 251 с. [Ilyina I.S., Lapshina Ye.I., Lavrenko N.N., Meltser L.I., Romanova Ye.A., Bogoyavlenskiy B.A., Makhno V.D. (1985) Vegetation cover of West-Siberian plain. Novosibirsk, Nauka, 251 p. (in Russian)]

Киприянова Л.М. (2008) Растительность реки Бердь и ее притоков (Новосибирская область, Западная Сибирь). Растительность России, 12: 21-38 [Kipriyanova L.M. (2008) Vegetation of the Berd River and its tributaries (Novosibirsk Region, West Siberia). Vegetation of Russia [Rastitelnost Rossii], 12: 21-38 (in Russian)]

Коваленко А.А. (2014) Синтаксономия сообществ пойменного эфемеретума (Isoëto-NanoJuncetea) Национального парка «Пирятинский» (Полтавская область, Украина). Ботанический журнал, 99(1): 34-60 [Kovalenko O.A. (2014) Syntaxonomy of flood-plain ephemerous vegetation (Isoëto-Nano-Juncetea) of the National Nature Park "Pyryatinsky" (Poltava Region, Ukraine). Bot. Zhurn., 99(1): 34-60 (in Russian)]

Кондратьев Н.Е., Попов И.В., Снищенко Б.Ф. (1982) Основы гидроморфологической теории руслового проиесса. Л., Гидрометеоиздат, 272 с. [Kondratyev N.E., Popov I.V., Snishchenko B.F. Foundations of the hydromorphological theory of channel process. Leningrad, Gidrometeoizdat, 272 p. (in Russian)]

Соломещ А.И., Гаврилов В.А. (1989) Синтаксономия водной и прибрежно-водной растительности Черемшанского залива Куйбышевского водохранилища. Деп. в ВИНИТИ 12.10.89, № 6232-B89. M., 15 c. [Solomeshch A.I., Gavrilov V.A. (1989) Syntaxonomy of water and amphibious vegetation of Cheremshan Bay of Kuybyshev Reservoir. Deposited in VINITI 12.10.89, No. 6232-B89. Moscow, 15 p. (in Russian)]

Соломещ А.И., Григорьев И.Н., Мулдашев А.А., Алимбекова Л.М. (1994) Растительный покров хребта Шайтан-тау. Дубравная лесостепь на хребте Шайтан-тау и вопросы ее охраны. Уфа, УНЦ РАН, с. 27-96 [Solomeshch A.I., Grigoriev I.N., Muldashev A.A., Alimbekova L.M. (1994) Vegetation cover of Shaytan-tau mountain ridge. Oakery forest-steppe on Shaytan-tau mountain ridge and problems of its protection. Ufa, Ufa Scientific Center of RAS, p. 27-96 (in Russian)] 
Таран Г.С. (1993) К синтаксономии пойменного эфемеретума Черного Иртыша. Сибирский биологический журнал, 5: 79-84 [Taran G.S. (1993) On syntaxonomy of Black Irtysh flood-plain ephemerous vegetation. Siberian Journal of Biology [Sibirskiy biologicheskiy zhurnal], 5: 79-84 (in Russian)]

Таран Г.С. (1994) Пойменный эфемеретум средней Оби - новый для Сибири класc IsoëtoNanojuncetea Br.-Bl. et Tx. 1943 на северном пределе распространения. Сибирский экологический журнал, 1(6): 595-599 [Taran G.S. (1994) Flood-plain ephemeretum of Middle Ob - a new class for Siberia, Isoëto-Nanojuncetea Br.-Bl. et Tx. 1943 on the northern border of expansion. Siberian Journal of Ecology, 1(6): 578-582]

Таран Г.С. (1995) Малоизвестный класс растительности бывшего СССР - пойменный эфемеретум (Isoëto-Nanojuncetea Br.-Bl. et Tx. 43). Сибирский экологический журнал, 2(4): 373-382 [Taran G.S. (1995) A little known vegetation class of the former USSR - flood-plain ephemeretum (Isoëto-Nanojuncetea Br.-Bl. et Tx. 43). Siberian Journal of Ecology, 2(4): 372380]

Таран Г.С. (2001) Ассоциация Суpero-Limoselletum (Oberd. 1957) Korneck 1960 (IsoëtoNanojuncetea) в пойме средней Оби. Растительность России, 1: 43-56 [Taran G.S. (2001) Association Cypero-Limoselletum (Oberd. 1957) Korneck 1960 (Isoëto-Nanojuncetea) in the middle Ob River floodplain. Vegetation of Russia [Rastitelnost Rossii], 1: $43-56$ (in Russian)]

Таран Г.С. (2005) Новая ассоциация пойменного эфемеретума - Rorippo dogadovaeLimoselletum aquaticae ass. nov. (Isoëto-Nanojuncetea). Биологические ресурсы и природопользование. Bып. 8. Сургут, Дефис, с. 66-72 [Taran G.S. (2005) New association of floodplain ephemeral vegetation - Rorippo dogadovae-Limoselletum aquaticae ass. nov. (Isoëto-Nanojuncetea). Biological resources and nature management, Iss. 8. Surgut, Defis, p. 66-72 (in Russian)]

Таран Г.С. (2009) Пойменный эфемеретум Оби и Иртыша у города Ханты-Мансийска. Вестник Оренбургского государственного университета, 2: 108-110 [Taran G.S. (2009) Bottomland ephemeretum of $\mathrm{Ob}$ and Irtysh Rivers near Khanty-Mansiysk city. Vestnik of the Orenburg State University [Vestnik Orenburgskogo gosudarstvennogo universiteta], 2: 108-110 (in Russian)]

Таран Г.С. (2015) Ивовые леса Оби и Иртыша в первый год развития. Ботанический журнал, 100(7): 658-675 [Taran G.S. (2015) Willow forests of the Ob and Irtysh Rivers in the first year of development. Bot. Zhurn., 100(7): 658-675 (in Russian)]

Таран Г.С., Тюрин В.Н. (2006) Очерк растительности поймы Оби у города Сургута. Биологические ресурсы и природопользование. Bыn. 9. Сургут, Дефис, с. 3-54 [Taran G.S., Tyurin V.N. (2006) Review of the Ob floodplain vegetation near Surgut city. Biological resources and nature management. Iss. 9. Surgut, Defis, p. 3-54 (in Russian)]

Таран Г.С., Саодатова Р.3. (2008) К характеристике пойменного эфемеретума нижнего Иртыша. Бюллетень Главного ботанического сада, 194: 94-101 [Taran G.S., Saodatova R.Z. (2008) On characterization of floodplain ephemeral vegetation of lower Irtish River. Bulletin of the Main Botanical Garden [Byulleten Glavnogo botanicheskogo sada], 194: 94-101 (in Russian)]

Тимохина С.A. (1990) Scirpus L. - Камыш. Флора Сибири. Суреraceae. T. 3. Новосибирск, Наука, c. 18-22 [Timokhina S.A. (1990) Scirpus L. - Club-rush. Flora of Siberia. Cyperaceae. Vol. 3. Novosibirsk, Nauka, p. 18-22 (in Russian)] 
Черепанов С.К. (1995) Сосудистые растения России и сопредельных государств (в пределах бывшего СССР). СПб., Мир и Семья-95, 992 с. [Czerepanov S.K. (1995) Vascular plants of Russia and adjacent states (the former USSR). Saint-Petersburg, Mir i Semya-95, 992 p. (in Russian)]

Шенников А.П. (1938) Луговая растительность СССР. Растительность СССР. Т. 1. М.-Л., Изд-во АН СССР, с. 429-638 [Shennikov A.P. (1938) Meadow vegetation of the USSR. Vegetation of the USSR. Vol. 1. Moscow-Leningrad, Academy of Sciences of the USSR, p. 429-638 (in Russian)]

Deil U. (2005) A review on habitats, plant traits and vegetation of ephemeral wetlands - a global perspective. Phytocoenologia, 35(2-3): 533-705

Hayasaka E. (2002) Taxonomic revision of the genus Schoenoplectus (Cyperaceae), with special reference to nutlet micromorphology. Doctoral Thesis. Sendai, Graduate School of Science, Tohoku University, $309 \mathrm{p}$.

Ignatov M.S., Afonina O.M., Ignatova E.A., Abolina A., Akatova T.V., Baisheva E.Z., Bardunov L.V., Baryakina E.A., Belkina O.A., Bezgodov A.G., Boychuk M.A., Cherdantseva V.Ya., Czernyadjeva I.V., Doroshina G.Ya., Dyachenko A.P., Fedosov V.E., Goldberg I.L., Ivanova E.I., Jukoniene I., Kannukene L., Kazanovsky S.G., Kharzinov Z.Kh., Kurbatova L.E., Maksimov A.I., Mamatkulov U.K., Manakyan V.A., Maslovsky O.M., Napreenko M.G., Otnyukova T.N., Partyka L. Ya., Pisarenko O.Yu., Popova N.N., Rykovsky G.F., Tubanova D.Ya., Zheleznova G.V., Zolotov V.I. (2006) Check-list of mosses of East Europe and North Asia. Arctoa, 15: 1-130

Konstantinova N.A., Bakalin V.A., Andrejeva E.N., Bezgodov A.G., Borovichev E.A., Dulin M.V., Mamontov Yu.S. (2009) Checklist of liverworts (Marchantiophyta) of Russia. Arctoa, 18: 1-64

Korneck D. (1960) Beobachtungen an Zwergbinsengesellschaften im Jahre 1959. Beitr. naturk. Forsch. SW-Dtschl., 19: 101-110

Mucina L., Bultmann H., Dierßen K., Theurillat J.-P., Raus T., Carni A., Sumberova K., Willner W., Dengler J., Garcıa R.G., Chytry M., Hajek M., Di Pietro R., Iakushenko I., Pallas J., Daniels F.J.A., Bergmeier E., Guerra A.S., Ermakov N., Valachovic M., Schaminee J.H.J., Lysenko T., Didukh Y.P., Pignatti S., Rodwell J.S., Capelo J., Weber H.E., Solomeshch A., Dimopoulos P., Aguiar C., Hennekens S.M., Tichy L. (2016) Vegetation of Europe: hierarchical floristic classification system of vascular plant, bryophyte, lichen, and algal communities. Applied Vegetation Science, 19 (Suppl. 1): 3-264

Oesau A. (1972) Zur Soziologie von Limosella aquatica L. Beitr. Biol. Pfl. (Berlin), 48: 377-397

Philippi G. (1992) Klasse: Isoëto-Nanojuncetea. Süddeutsche Pflanzengesellschaften. Teil I: Felsund Mauergesellschaften, alpine Fluren, Wasser-, Verlandungs- und Moorgesellschaften. 3 Auflage. Jena, Stuttgart, New-York, G. Fischer, p. 166-181

Pietsch W. (1973) Beitrag zur Gliederung der europäischen Zwergbinsengesellschaften (IsoëtoNanojuncetea Br.-B1. et Tx. 1943). Vegetatio, 28(5-6): 401-438

Rašomavičius V., Biveinis A. (1996) The communities of the Isoëto-Nanojuncetea bufonii Br.-Bl. et R. Tx. class in Lithuania. Botanica Lithuanica, 2(1): 3-25

Täuber T. (2000) Zwergbinsen-Gesellschaften (Isoëto-Nanojuncetea) in Niedersachsen Verbreitung, Gliederung, Dynamik, Keimungsbedingungen der Arten und Schutzkonzepte. 1. Aufl. Göttingen, Cuvillier, 238 p.

Weber H.E., Moravec J., Theurillat J.-P. (2000) International code of phytosociological nomenclature. $3^{\text {rd }}$ ed. Journal of Vegetation Science, 11(5): 739-768 